\title{
Bilateral Severe Mydriasis Due To Escitalopram
}

\author{
Mina Sherif Soliman Georgy \\ Neuropsychiatry Resident - Ain Shams University Hospitals, Cairo, Egypt.
}

Corresponding author: Mina Sherif Soliman Georgy, Neuropsychiatry Resident - Ain Shams University Hospitals, Cairo, Egypt.

Received date: December 14, 2019; Accepted date: January 06, 2020; published date: January 10, 2020

Citation: Mina Sherif SG (2020) Bilateral Severe Mydriasis Due To EscitalopramJ Clinical Research and Reports, 2(1);

DOI: $10.31579 /$ jcrr/2020/014

Copyright: (C) 2020 Mina Sherif SG. This is an open access article distributed under the Creative Commons Attribution License, which permits unrestricted use, distribution, and reproduction in any medium, provided the original work is properly cited.

A 22 year old male student was seen by a psychiatrist for the complaint of having no interest in studying for his final college examination accompanied with loss of appetite and sleep disturbance.

Upon taking psychiatric history, his symptoms were: diminished interest in daily activities of three months duration, fatigue, insomnia of sixth months duration, anorexia of two months duration and feelings of worthlessness. His physical examination and laboratory tests were normal with no abnormality.

Thus, the diagnosis of major depressive disorder was made based on the psychiatric evaluation and he was prescribed Escitalopram $10 \mathrm{mg}$ daily.

On the third day of the Escitalopram therapy, bilateral severe mydriasis was observed by the patient, after contacting the psychiatry department, he was referred for ophthalmological examination.

Upon ophthalmological examination, his examination revealed a right pupil diameter of $8 \mathrm{~mm}$ and a left pupil diameter of $8 \mathrm{~mm}$ with room light. Pupillary responses were equal with light exposure. The ophthalmological examination was reported as normal except for the unexplained bilateral mydriasis that was not ophthalmological in origin.

\section{Photographs were taken as a documentation:}

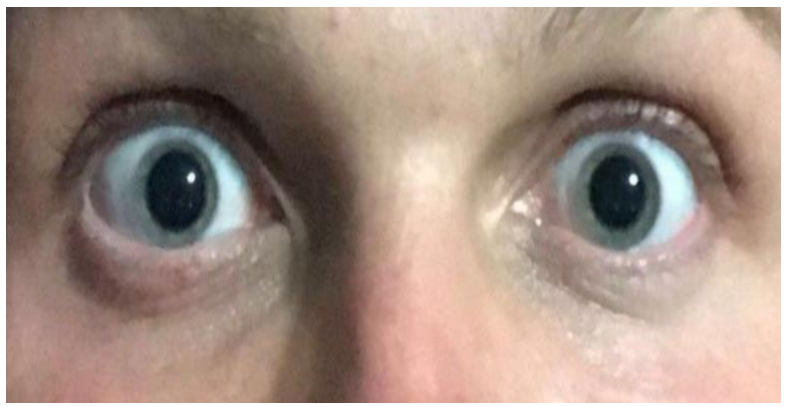

Figure.1: Bilateral Severe Mydriasis as seen after the use of Escitalopram. Courtesy of; Mina Sherif Soliman Georgy.

So, the patient was then referred for neurology and neurosurgery departments, in order to exclude the presence of any neurological or neurosurgical causes, however both examinations were also non conclusive with no neurological or neurosurgical abnormalities.

Upon excluding any organic cause for the bilateral mydriasis, the patient was referred back to the psychiatry department, Escitalopram was suspected as the cause for the bilateral mydriasis that wasn't present before initiating the treatment, so escitalopram treatment was discontinued, after four days the patient's pupils returned back to normal size.

Escitalopram was discontinued and alternatively Venlafaxine was initiated at $37.5 \mathrm{mg}$ per day that was titrated up to $150 \mathrm{mg}$ per day, and Venlafaxine was well tolerated for the patient after three months of follow up with no recurrence of the bilateral mydriasis.

The pupillary light reflex is normally responsible for the pupil dilatation in the dark environment in order to improve the visual acuity, and the pupil constriction in the light environment in order to protect the retina from sunlight damage during the day. However a mydriatic pupil will remain dilated and won't constrict even in a light environment or during the day light. (1)

Although, bilateral mydriasis is not a life-threatening condition, yet it is a symptom of a number of serious conditions including: brain tumor compressing the oculomotor nerve, cerebrovascular stroke, impending brain herniation, oculomotor neuropathy, head trauma and also sympathomimetic or anticholinergic drugs. (3) (4)

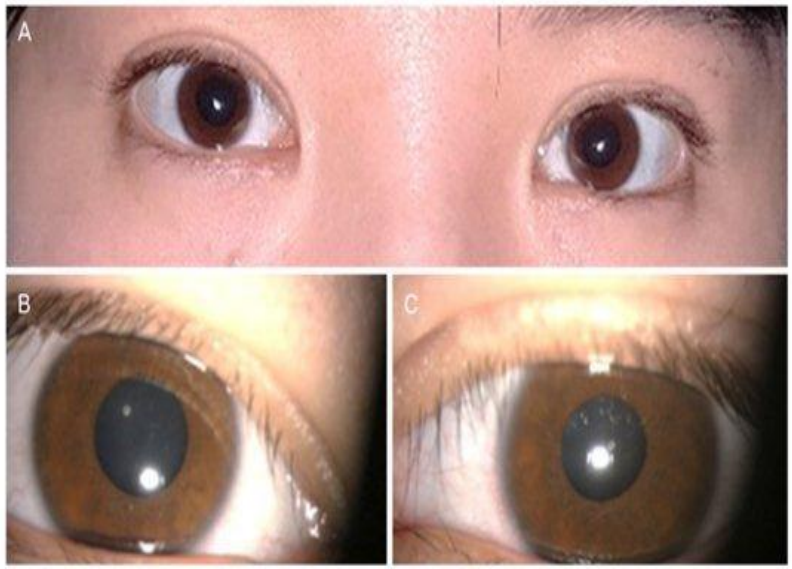

Figure.2: a case of benign episodic mydriasis Courtesy of Ye Rim Ahn et al.

Mydriasis or anisocoria are reported side effects with various SSRI drug class subtypes such as paroxetine or fluvoxamine but not escitalopram. (5)

Thus, more research into this matter is needed, in order to fully understand the SSRI drug class and the mechanism by which some patients experience bilateral mydriasis,is it an anticholinergic feature for the drug? Or is it another unknown mechanism? 


\section{References:}

1. Farlex Partner Medical Dictionary.

2. The American Heritage $\AA$ Medical Dictionary.

3. Sanders RD (2009). Cranial nerves III, IV, and VI: Oculomotor function. Psychiatry (Edgmont), 6(11), 34-39

4. Leknes S, Wessberg J, Ellingsen DM, Chelnokova O, Olausson $\mathrm{H}$ et al (2013) Oxytocin enhances pupil dilation and sensitivity to 'hidden' emotional expressions. Social Cognitive and Affective Neuroscience, 8(7), 741-749

5. Domes G, Steiner A, Porges SW, Heinrichs M (2013) Oxytocin differentially modulates eye gaze to naturalistic social signals of happiness and anger Psychoneuroendocrinology, 38(7), 11981202
This work is licensed under Creative Commons Attribution 4.0 License
To Submit Your Article Click Here: Submit Article

DOI: $10.31579 / 2641-0419 / 038$
Ready to submit your research? Choose Auctores and benefit from:

* fast, convenient online submission

* rigorous peer review by experienced research in your field

* rapid publication on acceptance

* authors retain copyrights

* unique DOI for all articles

* immediate, unrestricted online access

At Auctores, research is always in progress.

Learn more www.auctoresonline.org/journals/clinical-cardiology-andcardiovascular-interventions 